\title{
Effects of Quercetin Metabolites on Triglyceride Metabolism of 3T3-L1 Preadipocytes and Mature Adipocytes
}

\author{
Itziar Eseberri ${ }^{1,2}{ }^{\oplus}$, Jonatan Miranda ${ }^{1,2, *}$, Arrate Lasa ${ }^{1,2}$, Andrea Mosqueda-Solís ${ }^{1}$, \\ Susana González-Manzano ${ }^{3}$, Celestino Santos-Buelga ${ }^{3}$ (1) and Maria P. Portillo ${ }^{1,2}$ \\ 1 Nutrition and Obesity Group, Department of Nutrition and Food Science, University of the Basque \\ Country (UPV/EHU) and Lucio Lascaray Research Institute, 01006 Vitoria, Spain; \\ itziar.eseberri@ehu.eus (I.E.); arrate.lasa@ehu.eus (A.L.); andreamosqueda.s@gmail.com (A.M.-S.); \\ mariapuy.portillo@ehu.eus (M.P.P.) \\ 2 CIBERobn Physiopathology of Obesity and Nutrition, Institute of Health Carlos III (ISCIII), 28029 Madrid, \\ Spain \\ 3 Grupo de Investigación en Polifenoles (GIP-USAL), Facultad de Farmacia, Universidad de Salamanca, \\ Campus Miguel de Unamuno s/n, 37007 Salamanca, Spain; susanagm@usal.es (S.G.-M.); \\ csb@usal.es (C.S.-B.) \\ * Correspondence: jonatan.miranda@ehu.eus; Tel.: +34-945-014038
}

Received: 26 November 2018; Accepted: 9 January 2019; Published: 11 January 2019

\begin{abstract}
Quercetin $(Q)$ has rapid metabolism, which may make it worthwhile to focus on the potential activity of its metabolites. Our aim was to evaluate the triglyceride-lowering effects of $\mathrm{Q}$ metabolites in mature and pre-adipocytes, and to compare them to those induced by $\mathrm{Q}$. 3T3-L1 mature and pre-adipocytes were treated with $0.1,1$ and $10 \mu \mathrm{M}$ of $\mathrm{Q}$, tamarixetin (TAM), isorhamnetin (ISO), quercetin-3-O-glucuronide (3G), quercetin-3-O-sulfate (3S), as well as with $3 S$ and quercetin-4-O-sulfate (4S) mixture (3S+4S). Triglyceride (TG) content in both cell types, as well as free fatty acid (FFA) and glycerol in the incubation medium of mature adipocytes were measured spectrophotometrically. Gene expression was assessed by RT-PCR. In mature adipocytes, $\mathrm{Q}$ decreased TG at 1 and $10 \mu \mathrm{M}, 3 \mathrm{~S}$ metabolite at 1 and $10 \mu \mathrm{M}$, and 3S+4S mixture at $10 \mu \mathrm{M}$. 3S treatment modified the glucose uptake, and TG assembling, but not lipolysis or apoptosis. During differentiation, only $10 \mu \mathrm{M}$ of ISO reduced TG content, as did Q at physiological doses. In conclusion, $3 S$ metabolite but not ISO, 3G, $4 \mathrm{~S}$ and TAM metabolites can contribute to the in vivo delipidating effect of $\mathrm{Q}$.
\end{abstract}

Keywords: Quercetin; metabolites; adipocytes; triglycerides

\section{Introduction}

Quercetin (Q) is a polyphenol classified as a flavonoid, found, mainly in glycoside form, in a variety of foods including berries, onions and shallots, apples, tea and chocolate [1]. Some of its metabolites, such as Isorhamnetin (ISO) and quercetin-3-O-glucuronide (3G), are also present in several food sources [2]. It is estimated that the dietary intake of $Q$ is $5-40 \mathrm{mg} /$ day [3]. However, consumption can reach $200-500 \mathrm{mg} /$ day when fruits and vegetables are abundant in the diet, especially if they are eaten with their skin [4].

Obesity, defined as excess fat accumulation in white adipose tissue, plays a key role as a regulator of lipid storage and release. It can be developed by increasing adipocyte number (hyperplasia) and/or size (hypertrophy) [5]. When hyperplasia takes place, there is a stimulation of pre-adipocyte proliferation and further differentiation. This process, which promotes pre-adipocyte differentiation into mature adipocytes is known as adipogenesis [6]. Nevertheless, this increase in adipocyte number 
does not necessarily promote obesity directly. Instead, during childhood growth, it determines the lipid-storing capacity of adipose tissue and fat mass in adulthood [7].

For triglyceride synthesis and further storage, mature adipocytes need a source of fatty acids and of glycerol-3-P. Fatty acids can be obtained from triglycerides circulating as lipoproteins, due to the action of lipoprotein lipase (LPL), which can be synthesized de novo from Acetyl-CoA or can be taken-up directly from circulation through specific transporters. Glycerol-3-P comes from glucose metabolism, after glucose uptake from blood through the glucose transporter GLUT-4. These two molecules are assembled into triglycerides in a process catalyzed by several enzymes. TG stored in adipose tissue can be mobilized in the process known as lipolysis, mediated by three lipases, which implies a breakdown of stored triglycerides and subsequent release of fatty acids and glycerol.

$\mathrm{Q}$ has recently been shown to be a potential body fat-lowering molecule. Its positive impact on lipolysis, apoptosis, fatty acid uptake, inhibition of adipogenesis and reduction of lipogenesis has been proposed as its mechanism of action [8-12]. In addition, it seems that its effect on white adipose tissue is accompanied by muscle and liver mitochondrial biogenesis and by improved glycaemic control among other effects, resulting in it being a multi-target flavonoid for body fat reduction $[13,14]$. Not only abundant cell culture experiments $[8,10,15,16]$, but also animal studies have confirmed its usefulness in body fat reduction, mostly in obese animals [17-22]. However, studies in humans remain scarce [19,23-25]. A matter of concern in the use of $Q$ as a bioactive molecule is its rapid metabolism, and thus its low bioavailability. Chen et al. [26] determined that $60 \%$ of total quercetin ingested by rats was absorbed, and $55.8 \%$ of this absorbed amount was metabolized by the gut and $1.8 \%$ by the liver. After ingestion, $Q$ is transformed into an aglycone form in the small intestine, that in turn is further metabolized by glucuronidation, sulfatation and methylation reactions [27]. As a result, only a reduced amount of $Q$ and considerable amounts of metabolites reach the bloodstream. According to the literature, the most predominant metabolites in plasma are ISO, tamarixetin (TAM), 3G and quercetin-3-O-sulfate (3S) [28-31] (Figure 1), with glucuronide metabolites being those that appear in higher concentrations and sulfate and methylated those that appear in lower concentrations [32-34].
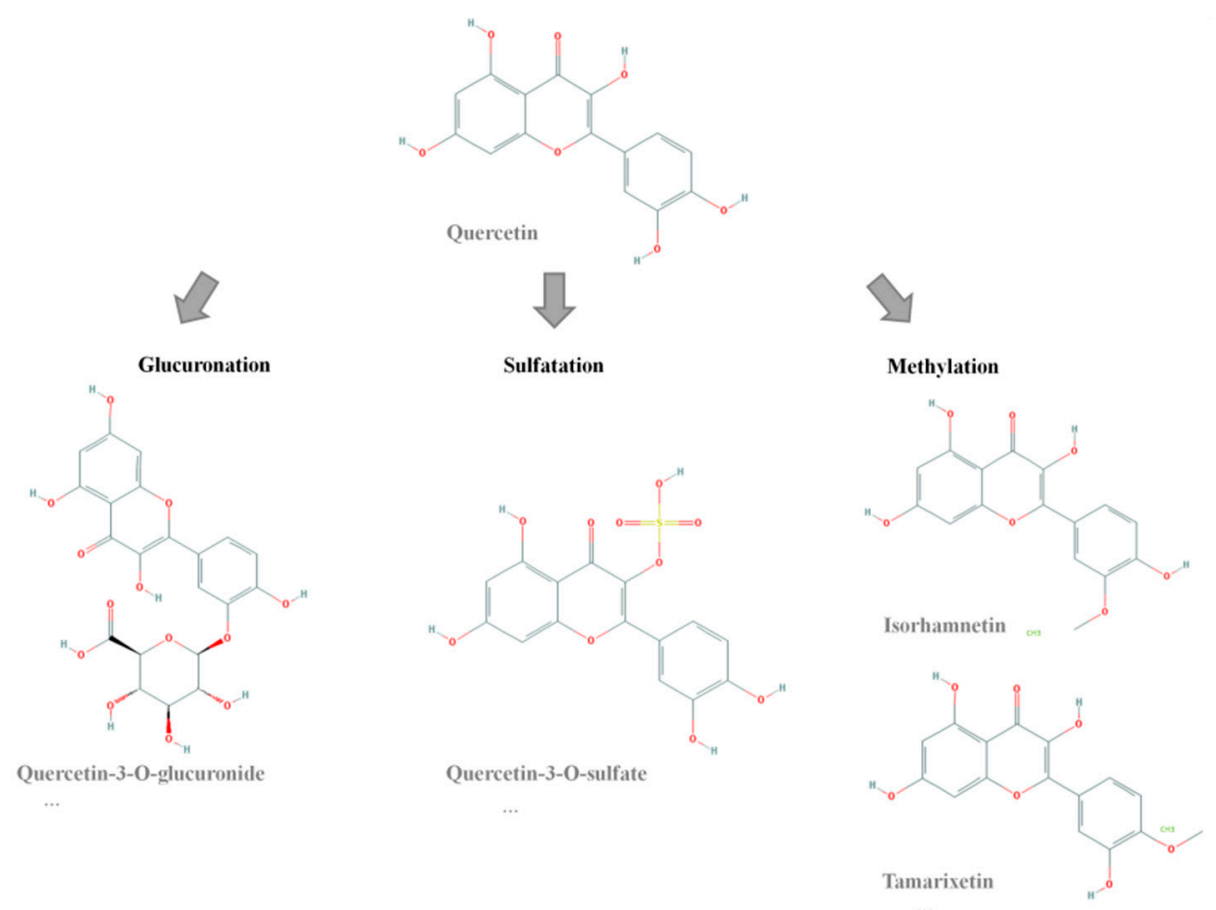

Figure 1. Chemical structures of $Q$ and its metabolites.

Bearing this in mind, it is not possible to be sure that the fat-lowering properties of $Q$ observed in in vivo experiments are exclusively attributable to $Q$. The potential activity of its metabolites should 
not be discarded. Data concerning this issue in adipocytes are scarce so far [35-37]. Studies carried out with these molecules in A549 lung cancer cells revealed that Q metabolites could have similar positive effects to those of $Q$ on cell invasion and migration [38].

Considering all these issues, in the present study we wanted to assess whether $Q$ and/or its metabolites are responsible for its beneficial effects in terms of delipidating molecule. For this purpose, the triglyceride-lowering effect of methylated metabolites TAM and ISO, 3G, $3 \mathrm{~S}$ and a mixture (3S+4S) of $3 \mathrm{~S}$ and quercetin-4-O-sulfate $(4 \mathrm{~S})$ in pre-adipocytes and mature adipocytes was evaluated and compared to that induced by $\mathrm{Q}$.

\section{Results and Discussion}

In order to address the challenge of determining delipidating capacity of each $\mathrm{Q}$ metabolite, several approaches with isolated TAM, ISO, 3G, 3S, and 3S+4S mixture dissolved in ethanol were performed in mature and maturing murine adipocytes. With regard to cell treatment, two aspects must be pointed out. First, the final concentration of ethanol per adipocyte was well below $0.1 \%$, a previously reported non-toxic concentration [39-42]. Secondly, the assays were conducted with doses lower than those commonly used in cell culture experiments $(0.1,1$ and $10 \mu \mathrm{M})$. One of the reasons for choosing these doses is related to the prevention of cell integrity, because $10 \mu \mathrm{M}$ of ISO and 3G was declared as safe in Raw 2647 cells, but toxic effects were observed for both molecules at 25 and $100 \mu \mathrm{M}$, respectively [43]. Moreover, in vivo supplementation studies are commonly carried out by using doses of $Q$ that lead to plasma $Q$ and $Q$ metabolite concentrations in the range of nanomolar and micromolar [44,45]. In addition, in previous studies from our laboratory, doses of $Q$ in the range of serum concentrations $(\leq 10 \mu \mathrm{M})$ were tested in adipocytes, revealing a dose-dependent effect on triglyceride (TG) reduction in pre-adipocytes [12].

Apart from commercially available metabolites TAM, ISO and 3G, hemisynthetized quercetin sulfate mixture (3S+4S) and $3 S$ were also used for the present study. Supplementary Figure S1 shows the HPLC chromatograms recorded at $370 \mathrm{~nm}$ with the two obtained fractions. In the case of the mixture, $4 \mathrm{~S}$ and $3 \mathrm{~S}$ represented $33.4 \%$ and $62.5 \%$ of the recorded peak areas, respectively.

No significant changes in mature adipocyte TG content were observed when these cells were incubated with the lowest dose $(0.1 \mu \mathrm{M})$ of the molecules studied. At a dose of $1 \mu \mathrm{M}$, only the $3 \mathrm{~S}$ metabolite, among all the molecules tested, reduced TG content. Finally, at $10 \mu \mathrm{M}, \mathrm{Q}, 3 \mathrm{~S}+4 \mathrm{~S}$ and $3 \mathrm{~S}$ significantly reduced TG content in adipocytes $(21 \%, 20 \%$ and $32 \%$, respectively). By contrast, $3 \mathrm{G}$, ISO and TAM were ineffective (Figure 2). Similar results were reported by Lee et al. with ISO treatment in mature adipocytes [35].

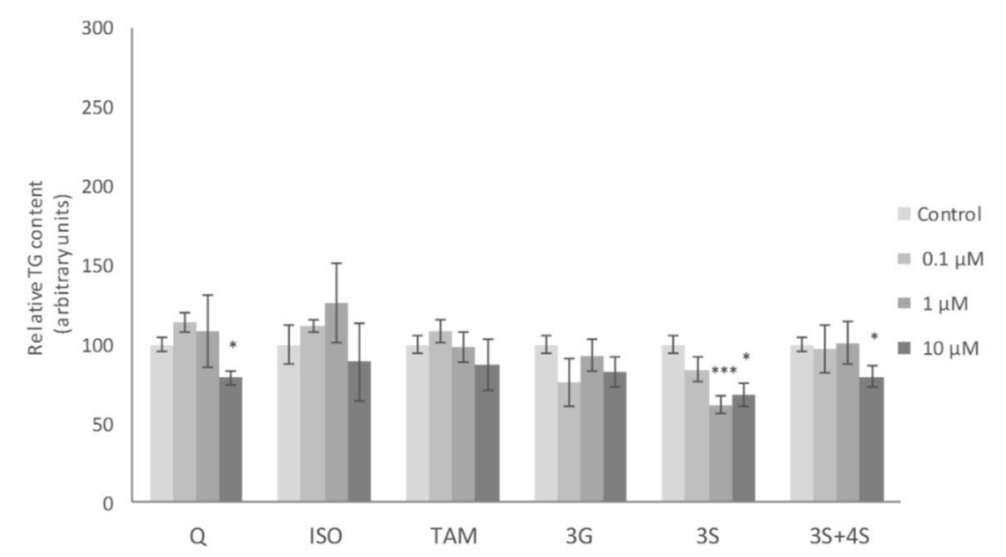

Figure 2. Effects of $0.1,1$ and $10 \mu \mathrm{M}$ of quercetin (Q), isorhamnetin (ISO), tamarixetin (TAM), quercetin-3-O-glucuronide (3G), quercetin-3-O-sulfate (3S), as well as $3 \mathrm{~S}$ and quercetin-4-O-sulfate (4S) mixture $(3 \mathrm{~S}+4 \mathrm{~S})$ on triacylglycerol content of 3T3-L1 mature adipocytes treated for $24 \mathrm{~h}$. Values are means \pm SEM. Comparison between each flavonoid dose and the control was analyzed by Student's $t$-test. The asterisks represent differences versus the controls $\left({ }^{*} p<0.05 ;{ }^{* * *} p<0.001\right)$. 
In order to explain the TG reduction observed, gene expression of mature adipocyte-specific genes was analyzed at the dose of $10 \mu \mathrm{M}$. We chose the highest dose to carry out this analysis because this was the active one for a great number of the molecules analyzed. Treatment with $10 \mu \mathrm{M}$ of $3 \mathrm{~S}$ significantly decreased and $3 \mathrm{~S}+4 \mathrm{~S}$ tended to reduce lipoprotein lipase (lpl) expression (Figure 3A,B). Evidence confirmed that adipocyte-derived LPL is required for efficient fatty acid uptake and further TG storage in 3T3-L1 adipocytes [46]. It is true that LPL is not determining in in vitro TG accumulation. However, the reduction observed could suggest a positive mechanism of action in in vivo situation. With regard to lipolysis, treatment with $3 \mathrm{~S}+4 \mathrm{~S}$ tended to reduce adipose triglyceride lipase (atgl) expression $(p=0.09)$ in mature adipocytes and thus, in order to clarify whether this change could result in changes in this metabolic pathway, glycerol and FFA release were measured (Supplementary Figure S2). Given that, as previously reported with Q [12], no changes were observed and consequently, it seems that lipolysis is not involved in TG reduction. On the other hand, even though further analysis is needed in order to confirm this fact, it can be proposed that $3 \mathrm{~S}$ metabolite, alone or in combination with $4 \mathrm{~S}$, could act reducing fatty acid uptake.

According to research conducted with adipose tissue explants from lean, overweight, obese and morbidly obese subjects, body fat mass increase is associated with CASP3 and P53 expression elevation and BCL2 expression reduction [47]. Thus, as the apoptotic pathway is related to adipose tissue homeostasis, the potential involvement of $3 S$ metabolite in apoptosis was studied. It promoted remarkably elevated levels of trp53, a gene that codifies tumor suppressor p53 protein. While p53 is linked with apoptosis, it has many other roles including cell-cycle arrest, DNA repair or senescence [48]. Due to this fact, other apoptosis-related genes such as caspase 3 (cas3) and the anti-apoptotic gene $b c l 2$ were assessed (Figure 3A). The expression of both genes revealed apoptosis reduction, instead of promotion with $3 \mathrm{~S}$ treatment ( $b c l 2$ elevation and cas 3 decrease). Thus, apoptosis does not represent a mechanism of action for $3 S$ metabolite in mature adipocytes. In fact, when $4 S$ was included there was no effect on apoptotic genes. Although the mixture $3 S+4 S$ raised the expression of trp53, no changes were observed in cas3 or bcl2 genes (Figure 3B).

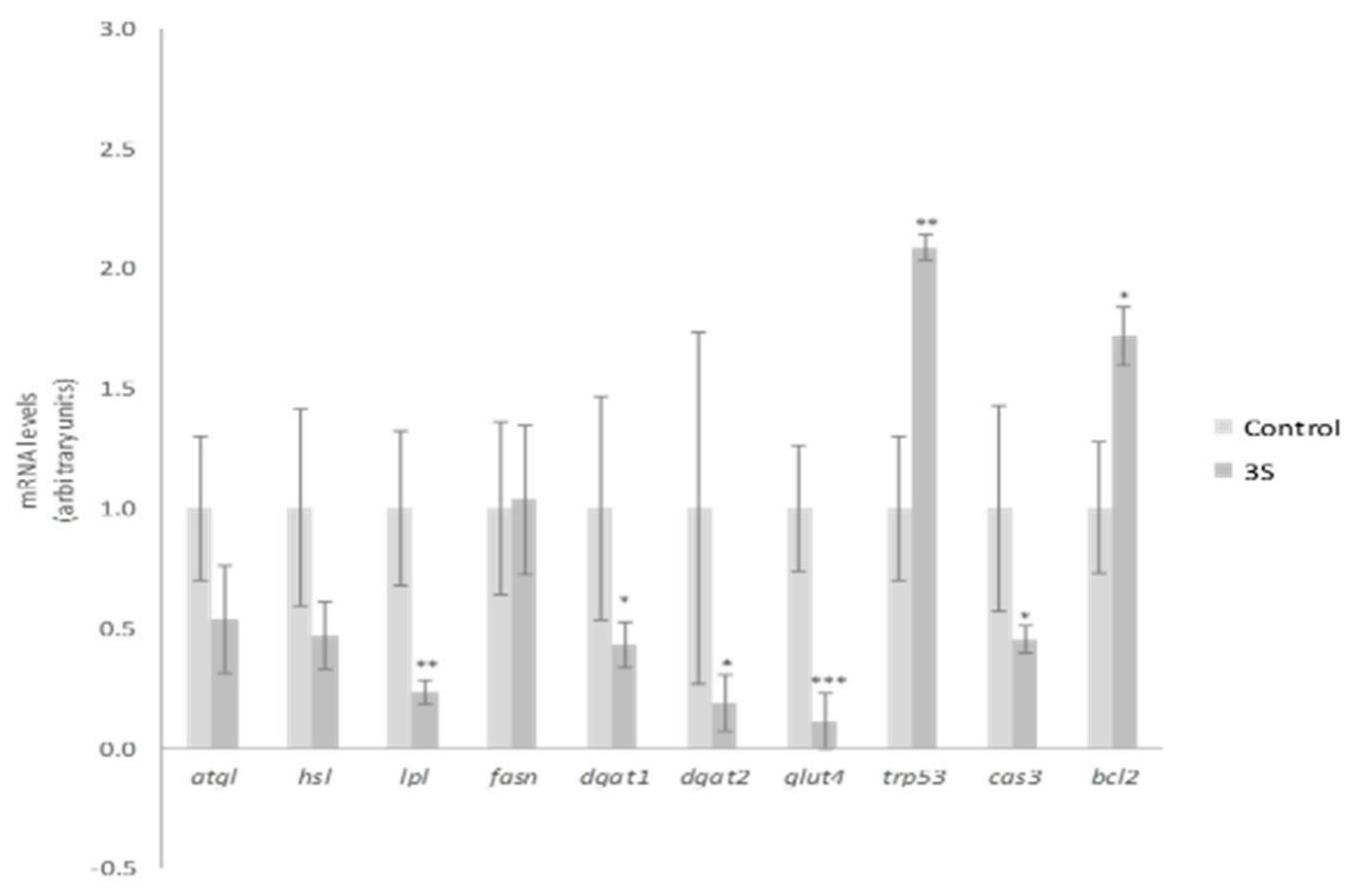

(A)

Figure 3. Cont. 


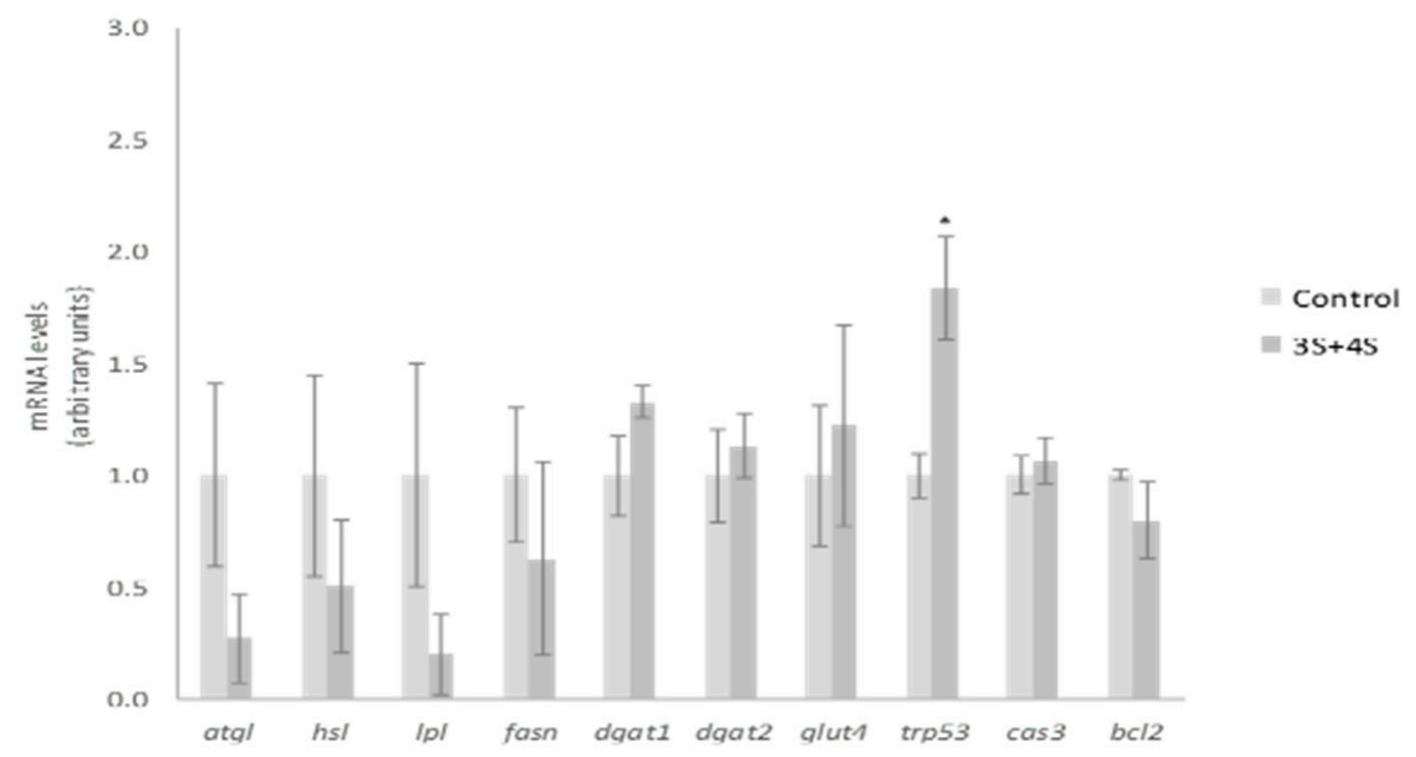

(B)

Figure 3. Effects of quercetin-3-O-sulfate (3S) (A) and quercetin-3-O-sulfate and quercetin-4-O-sulfate mixture (3S+4S) (B) at a dose of $10 \mu \mathrm{M}$ on the expression of atgl, hsl, lpl, fasn, dgat1, dgat2, glut4, trp53, cas3 and bcl 2 in 3T3-L1 mature adipocytes treated for $24 \mathrm{~h}$. Values are means \pm SEM. Comparison of $3 S$ or3S $+4 S$ and the control for each gene expression was analyzed by Student's $t$-test. The asterisks represent differences versus the controls $\left({ }^{*} p<0.05 ;{ }^{* *} p<0.01 ;{ }^{* * *} p<0.001\right)$.

Apart from fatty acid uptake, lipolysis and apoptosis, lipogenesis is another crucial metabolic process involved in fat storage. Uptaken fatty acids or new synthesized ones must be assembled with glycerol in order to accumulate triglyceride inside the adipocyte. As a result, facilitated glucose transporter member 4 (glut4), as well as diacylglycerol o-acyltransferase (dgat), genes involved in glucose uptake and TG assembly, can be considered limiting genes for TG synthesis. 3S, but not 3S+4S, reduced glut4, dgat1 and dgat2 gene expression (Figure 3A,B). By contrast, fatty acid synthase (fasn) related to de novo lipogenesis was not modified by the analyzed molecules. These results suggest that the synthesis of fatty acids is not affected by $Q$ metabolite treatment and TG assembly is reduced.

As far as we know this is the first study to reveal the potential effectiveness of $Q$ metabolites in mature adipocytes, postulating that glucose uptake and TG assembling are mechanisms that could justify the TG reduction observed in mature adipocyte after $3 S$ treatment. Consequently, the effects on body fat observed in animals after $\mathrm{Q}$ administration would be due not only to the parent compound but also to this metabolite. It is important to highlight that the addition of $4 S$ metabolite to $3 S$ did not confer any additional effect. In fact, the expression of evaluated genes revealed a decrease in their impact (Figure 3B). These results suggest that the TG-lowering effect can be attributed exclusively to $3 S$ metabolite, and that the addition of $4 S$ results in a dilution of the effective molecule.

It has been described that adipocyte turnover rate for lean and obese humans is around 10\% [7]. As mature adipocytes do not have the ability to divide, adipocyte precursors with this capacity must exist in adipose tissue. For this reason, in addition to mature adipocyte analysis, the effects of $Q$ metabolites on pre-adipocytes were also assessed in the present study. ISO has been the most studied of all the $\mathrm{Q}$ metabolites in maturing adipocytes. It has been demonstrated that this metabolite reduces TG accumulation, with $10 \mu \mathrm{M}$ the most effective dose in 3T3-L1 and human adipose tissue-derived stems cells $[35,49]$. Zhang et al. also reported similar results in 3T3-L1 pre-adipocytes, $12.5 \mu \mathrm{M}$ being the lowest effective dose [37]. In good accordance with these studies, a significant reduction after $10 \mu \mathrm{M}$ ISO treatment was observed in maturing pre-adipocytes in the present work. Nevertheless, none of the remaining $Q$ metabolites was able to reduce $T G$ at the doses of 1 or $10 \mu \mathrm{M}$, as $\mathrm{Q}$ did (Figure 4). 


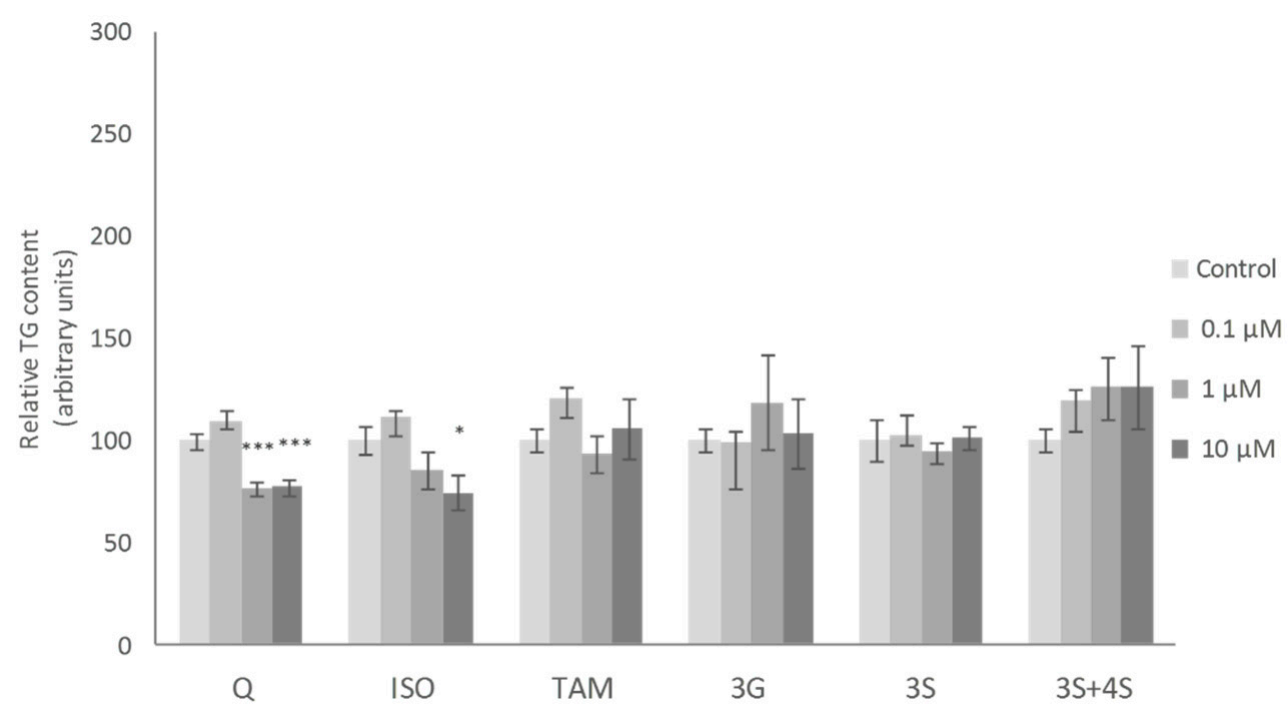

Figure 4. Effects of $0.1,1$ and $10 \mu \mathrm{M}$ of quercetin (Q), isorhamnetin (ISO), tamarixetin (TAM), quercetin-3-O-glucuronide (3G), quercetin-3-O-sulfate (3S), as well as $3 \mathrm{~S}$ and quercetin-4-O-sulfate (4S) mixture (3S+4S) on triacylglycerol content of 3T3-L1 maturing pre-adipocytes treated from day 0 to day 8 . Values are means \pm SEM. Comparison between each flavonoid dose and the control was analyzed by Student's $t$-test. The asterisks represent differences versus the controls $\left({ }^{*} p<0.05 ;{ }^{* * *} p<0.001\right)$.

With regard to the mechanisms of action for ISO, Lee et al. [35] demonstrated that nine days of treatment in maturing 3T3-L1 pre-adipocytes with $50 \mu \mathrm{M}$ reduced adipogenesis through the inhibition of peroxisome proliferator-activated receptor $\gamma$ (ppar $\gamma$ ) and CCAAT/enhancer-binding protein $\alpha$ (cebp $\alpha)$. In our cell cultures, the dose of $10 \mu \mathrm{M}$ tended to decrease ppary gene expression $(p=0.06)$, but not that of cebp $\alpha, c e b p \beta$ or sterol regulatory element-binding factor (srebf1) (Figure 5). By comparing both studies, it is clear that higher doses promote greater impact on adipogenesis inhibition. This conclusion was also reached by Zhang et al. [37], who revealed that ISO treatment decreased adipocyte differentiation at a concentration of $12.5 \mu \mathrm{M}$ and totally blocked this process at $50 \mu \mathrm{M}$. Likewise, they proposed the differentiation stage as a limiting step for ISO effect. According to their data, the inhibitory effect on adipogenesis was less prominent when ISO was added at the latter stages of differentiation. Moreover, they indicated that ISO may control the early differentiation stage by inhibiting the transactivation of ppary. In the present research, we treated 3T3-L1 pre-adipocytes with ISO throughout the adipogenic process (eight days). Therefore, the weak effect on ppary expression observed could be due not only to the low dose but also to the influence of the differentiating stage.

Much as took place with $3 \mathrm{~S}$ metabolite treatment of mature adipocytes, the expression of trp53 was increased after ISO treatment of differentiating pre-adipocytes, but a diminution of mRNA levels of the death repressor bcl2 was observed (Figure 5). Furthermore, ISO treatment did not promote any change in cas3 expression. These results reveal that the apoptosis pathway was not completely activated by ISO treatment, probably due to the low dose used. Mirroring mature adipocyte gene analysis, the expression of dagt1, dgat2, and glut 4 was also evaluated. With the exception of glut4, no changes in the genes mentioned were detected (Figure 5). Therefore, glucose uptake and TG assembly did not justify the observed delipidating effect of ISO.

In spite of the significant effects observed in the expression of several genes the only $\mathrm{Q}$ metabolite to induce a significant reduction in pre-adipocyte TG content was ISO, but at $10 \mu \mathrm{M}$, a dose higher than that found in serum when animals are treated with $Q$. Bearing this fact in mind, the involvement of $\mathrm{Q}$ metabolites in the anti-obesity effect of this phenolic compound cannot be proposed. 


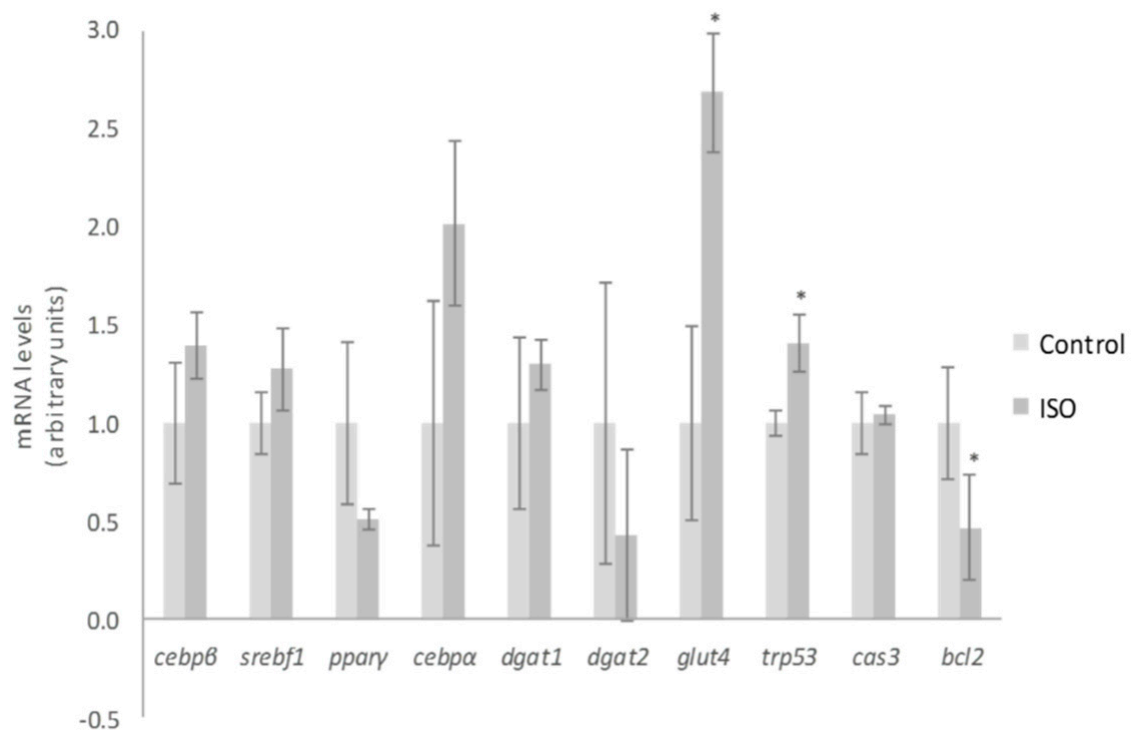

Figure 5. Effects of $10 \mu \mathrm{M}$ of isorhamnetin (ISO) on the expression of cebp $\beta$, srebf1, ppar $\gamma$, cebp $\alpha$, dgat1, dgat2, glut4, trp53, cas3 and bcl2 in 3T3-L1 adipocytes treated for from day 0 to day 8 . Values are means \pm SEM. Comparison between ISO and the control for each gene expression was analyzed by Student's $t$-test. The asterisks represent differences versus the control $\left({ }^{*} p<0.05\right)$.

\section{Materials and Methods}

\subsection{Reagents}

Dulbecco's modified Eagle's medium (DMEM) was purchased from GIBCO (BRL Life Technologies, Grand Island, NY, USA). Q was purchased from Sigma (St. Louis, MO, USA) and ISO, TAM, and 3G from Extrasynthese (Genay, France). TG were quantified by Infinity Triglycerides reagent (Thermo Electron Corporation, Rockford, IL, USA) and protein concentrations of cell extracts were measured with bicinchoninic acid (BCA) reagent (Thermo Scientific, Rockford, IL, USA). Commercial kits for analyzing FFA and free glycerol were supplied by Roche and Sigma respectively (Free Fatty Acids, Half Micro Test, Roche, Basilea, Sweden and F6428, Sigma, St. Louis, MO, USA).

\subsection{Synthesis of Quercetin-3-O-Sulfate and Quercetin-4-O-Sulfate Metabolites}

\subsubsection{Synthesis of Quercetin Sulfates}

Quercetin sulfates were synthesized as described by Dueñas et al. [50]. Dry pyridine was added to quercetin $(500 \mathrm{mg})$ to remove possible water associated with quercetin. Pyridine was rotary evaporated, and the dry compound was dissolved in dioxane $(50 \mathrm{~mL})$ and allowed to react in a water bath $\left(40{ }^{\circ} \mathrm{C}\right)$ for 90 min with a 10-fold molar excess of sulfur trioxide- $N$-triethylamine complex under nitrogen to avoid contact with air. Products of sulfation precipitated out and stuck to the glass. Dioxane was decanted, and the precipitate was redissolved in $10 \%$ methanol in water. The mixtures of quercetin sulfates were fractioned on a Sephadex LH-20 column $(350 \mathrm{~mm} \times 30 \mathrm{~mm})$, successively eluted with $10 \%$ aqueous ethanol $(500 \mathrm{~mL})$ and $20 \%$ aqueous ethanol $(500 \mathrm{~mL})$. The fractions containing monosulfates were collected, concentrated to dryness under vacuum, redissolved in ultrapure water, and analyzed by high-performance liquid chromatography with diode array and mass spectrometry detection (HPLC-DAD-MS).

\subsubsection{HPLC-DAD-MS Analyses}

Analyses were carried out with a Hewlett-Packard 1100 chromatograph (Agilent Technologies, Waldbronn, Germany) with a quaternary pump and a DAD coupled to a HP Chem Station (revision 
A.05.04) data-processing station. Separation was achieved on an Agilent Poroshell 120 EC-C18 column $(2.7 \mu \mathrm{m}, 150 \mathrm{~mm} \times 4.6 \mathrm{~mm})$ thermostatted at $35{ }^{\circ} \mathrm{C}$. Solvents used were (A) $0.1 \%$ TFA in water and (B) acetonitrile and the elution gradient was from 10 to $15 \%$ B for $5 \mathrm{~min}$, from 15 to $25 \%$ B for $5 \mathrm{~min}$, from 25 to $35 \%$ B over $10 \mathrm{~min}$, from 35 to $50 \%$ B over $10 \mathrm{~min}$, isocratic $50 \%$ B for $10 \mathrm{~min}$, and re-equilibration of the column, at a flow rate of $0.5 \mathrm{~mL} / \mathrm{min}$. Double online detection was carried out in the DAD using 250 and $370 \mathrm{~nm}$ as preferred wavelengths and in a mass spectrometer connected to the HPLC system via the DAD cell outlet. MS detection was performed in a Finnigan LCQ detector (Thermoquest, San Jose, CA, USA) equipped with an ESI source and an ion-trap mass analyzer, which were controlled by the LCQ Xcalibur software. Both the auxiliary and sheath gases were nitrogen at flow rates of 20 and $80 \mathrm{~L} / \mathrm{min}$, respectively. The source voltage was $4.5 \mathrm{kV}$; the capillary voltage was $11 \mathrm{~V}$; and the capillary temperature was $220^{\circ} \mathrm{C}$. Spectra were recorded in negative-ion mode between $m / z 150$ and 2000. The MS detector was programmed to perform a series of two consecutive scans: a full scan and a MS-MS scan of the most abundant ion in the first scan, using a normalized collision energy of $45 \%$.

\subsubsection{Identification and Quantification of Quercetin Sulfates}

Chemical hemisynthesis of the quercetin sulfates was performed as described by Dueñas et al. [50]. The complex mixture of products obtained was fractionated on a Sephadex LH-20 column to separate monosulfates from other products (quercetin and quercetin disulfates). Further fractionation by semipreparative HPLC obtained pure quercetin sulfate and a mixture with two quercetin sulfates that were freeze dried for further use.

Chromatograms peaks showed a pseudomolecular ion [M-H]- at $m / z 381$ that released a unique fragment at $m / z 301$ ( $-80 \mathrm{amu}$, loss of a sulfate moiety), corresponding to quercetin. The peaks were identified as quercetin 4'-O-sulfate (peak 1) and quercetin 3'-O-sulfate (peak 2) based on their comparison with compounds previously synthesized and fully identified by NMR [50]. The chromatographic purity of the compounds was calculated to be higher than $96 \%$ from the area of the peaks obtained in HPLC chromatograms recorded at 370 and $250 \mathrm{~nm}$.

\subsection{Experimental Design}

3T3-L1 pre-adipocytes, supplied by American Type Culture Collection (Manassas, VA, USA), were cultured in DMEM containing 10\% fetal calf serum (FCS). Two days after confluence (day 0 ), cells were stimulated to differentiate with DMEM containing $10 \%$ FCS, $10 \mu \mathrm{g} / \mathrm{mL}$ insulin, $0.5 \mathrm{mM}$ isobutylmethylxanthine, and $1 \mu \mathrm{M}$ of dexamethasone for two days. From day four onward, the differentiation medium was replaced by FBS/DMEM medium (10\%) containing $0.2 \mu \mathrm{g} / \mathrm{mL}$ insulin. This medium was changed every two days until cells were harvested. All media contained 1\% Penicillin/Streptomycin $(10,000 \mathrm{U} / \mathrm{mL})$, and the media for differentiation and maturation contained $1 \%(v / v)$ of Biotin and Pantothenic Acid. Cells were maintained at $37{ }^{\circ} \mathrm{C}$ in a humidified $5 \%$ $\mathrm{CO} 2$ atmosphere.

\subsection{Cell Treatment}

For the treatment of mature adipocytes, cells grown in 6-well plates were incubated with $\mathrm{Q}, \mathrm{ISO}$, TAM, 3G, 3S and 3S+4S at $0.1,1$ and $10 \mu \mathrm{M}$ (diluted in 95\% ethanol) on day 12 after differentiation, because at that day $>90 \%$ of cells developed mature with visible lipid droplets. In the case of the control group, the same volume of the vehicle (ethanol 95\%) was used. Vehicle was diluted 1000-fold in each well, reaching a final concentration of $0.095 \%$. After $24 \mathrm{~h}$, the supernatant was collected and cells were used for TG determination, quantification of glycerol and FFA in the media and RNA extraction. Each experiment was performed three times.

For the treatment of maturing pre-adipocytes, cells grown in 6-well plates were incubated with $\mathrm{Q}, \mathrm{ISO}, \mathrm{TAM}, 3 \mathrm{G}, 3 \mathrm{~S}$ and $3 \mathrm{~S}+4 \mathrm{~S}$ at $0.1,1$ and $10 \mu \mathrm{M}$ (diluted in $95 \%$ ethanol) during differentiation. In the case of the control group, the same volume of the vehicle (ethanol 95\%) was used. Media 
containing, or not, molecules were changed every two days: on day 0 , day 2 , day 4 , and day 6 . On day 8 , the supernatant was collected and cells were used for TG determination, RNA extraction and protein extraction. Each experiment was performed three times.

\subsection{Measurement of Triacylglycerol Content}

After treatment, the medium was removed and cell extracts were used for TG determination. Maturing pre-adipocytes and mature adipocytes were washed extensively with phosphate-buffered saline and incubated three times with $800 \mu \mathrm{L}$ of hexane/isopropanol (2:1). The total volume was then evaporated by vacuumed centrifugation and the pellet was resuspended in $200 \mu \mathrm{L}$ Triton X-100 in $1 \%$ distilled water. Afterwards, TGs were disrupted by sonication and the content was measured by means of a commercial kit. For protein determinations, cells were lysed in $0.3 \mathrm{~N} \mathrm{NaOH}, 0.1 \%$ SDS. Protein measurements were performed using the BCA reagent. TG content values were obtained as $\mathrm{mg}$ triacylglycerols/mg protein and converted into arbitrary units.

\subsection{RNA Extraction and RT-PCR}

RNA samples from cells treated were extracted using Trizol (Invitrogen, Carlsbad, CA, USA), according to the manufacturer's instructions. After RNA purity verification, samples were then treated with DNase I kit (Applied Biosystems, Foster city, CA, USA) to remove any contamination with genomic DNA. $1.5 \mu \mathrm{g}$ of total RNA of each sample was reverse-transcribed to first-strand complementary DNA (cDNA) using iScriptTM cDNA Synthesis Kit (Bio-Rad, Hercules, CA, USA).

Relative $a t g l, h s l, l p l, f a s n, g l u t 4$, dgat1, dgat2, bcl2, trp53 and cas3 mRNA levels in mature adipocytes and relative $\operatorname{cebp} \alpha$ and $\operatorname{cebp} \beta$, srebf1, ppar $\gamma$, glut4, dgat1, dgat2, bcl2, trp53 and cas3 mRNA levels in maturing pre-adipocytes were quantified using Real-Time PCR with an iCyclerTM - MyiQTM Real Time PCR Detection System (BioRad, Hercules, CA, USA). For atgl, hsl, lpl, fasn, cebp $\beta$, srebf1 and bcl2 SYBR Green Master Mix (Applied Biosystems, Foster City, CA, USA) was used. The upstream and downstream primers and probe (TibMolbiol, Berlin, Germany, Eurogentec, Liège, Belgium and

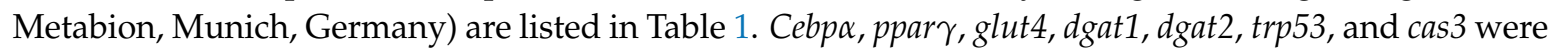
measured by TaqMan ${ }^{\circledR}$ Gene Expression Assays (Mm00514283_s1, Mm00440940_m1, Mm01731290_g1, Mm00436615_m1, Mm00515643_m1, Mm499536_m1, Mm01195085_m1 and Mm02619580_g1) and TaqMan ${ }^{\circledR}$ Fast Advanced Master Mix (Applied Biosystems, Foster City, CA, USA). RT-PCR parameters used were those defined by manufacturer's. $\beta$-actin mRNA levels were similarly measured and served as the reference gene.

Table 1. Primers for PCR amplification of each studied gene.

\begin{tabular}{|c|c|c|c|}
\hline Gene & Sense Primer & Anti-Sense Primer & Annealing $\mathrm{t}^{\mathrm{a}}\left({ }^{\circ} \mathrm{C}\right)$ \\
\hline atgl & 5'-GAGCTTCGCGTCACCAAC-3' & 5'-CACATCTCTCGGAGGACCA-3' & 60.0 \\
\hline hsl & $5^{\prime}$-GGTGACACTCGCAGAAGACAATA- $3^{\prime}$ & 5'-GCCGCCGTGCTGTCTCT-3' & 60.0 \\
\hline$l p l$ & 5'-CAGCTGGGCCTAACTTTGAG-3' & $5^{\prime}$-ССТСТСТGСАATCACACGAA-3' & 61.5 \\
\hline fasn & $5^{\prime}$-AGCCCCTCAAGTGCACAGTG-3' & 5'-TGCCAATGTGTTTTCCCTGA-3' & 60.0 \\
\hline$\beta$-actin & 5'-ACGAGGCCCAGAGCAAGAG-3' & $5^{\prime}$-GGTGTGGTGCCAGATCTTCTC-3' & 60.0 \\
\hline srebf1 & 5’- GCTGTTGGCATCCTGCTATC-3' & 5'-TAGCTGGAAGTGACGGTGGT-3' & 60.0 \\
\hline$c е b p \beta$ & 5'-CAAGCTGAGCGACGAGTACA-3' & 5'-CAGCTGСТССАССТТСТТСТ-3' & 67.5 \\
\hline$b c l 2$ & 5'-AGTACCTGAACCGGCATCTG-3' & 5'-GGGGCCATATAGTTCCACAAA-3' & 60.0 \\
\hline
\end{tabular}

atgl = adipose triglyceride lipase; $h s$ = hormone sensitive lipase; $l p l=$ lipoprotein lipase; fasn= fatty acid synthase; srebf $1=$ sterol regulatory element-binding factor $1 ; \operatorname{cebp} \beta=$ CCAAT-enhancer- binding protein $\beta ;$ bcl $2=B$ cell leukemia/lymphoma 2.

All gene expression results were expressed as fold changes of threshold cycle $(\mathrm{Ct})$ value relative to controls using the $2^{-\Delta \Delta C t}$ method [51]. 


\subsection{Measurements of Glycerol and Free Fatty Acids in the Media}

After treatment in mature adipocytes, aliquots of the medium treated with $10 \mu \mathrm{M}$ of $3 \mathrm{~S}+4 \mathrm{~S}$ were removed and analyzed for glycerol and FFA quantification by means of commercial kits (see Reagents paragraph).

\subsection{Statistical Analysis}

Results are presented as mean \pm standard error of the mean (SEM). Statistical analysis was performed using SPSS 24.0 (SPSS Inc., Chicago, IL, USA). After confirming the normal distribution of variables using Shapiro-Wilks normality test, each flavonoid dose effect against the control was checked by Student's $t$ test. Statistical significance was set-up at the $p<0.05$ level.

\section{Conclusions}

The results obtained in the present study demonstrate that $3 S$ metabolite may contribute to the delipidating effect of $Q$ by reducing glucose uptake and TG assembling in mature adipocytes. ISO metabolite diminished TG accumulation in pre-adipocytes, but at a concentration of $10 \mu \mathrm{M}$, which is higher than that found in plasma from animals treated with Q. Consequently, its contribution to the effect of $Q$ should be discarded, as well as that of $3 G, 4 S$ and TAM.

Supplementary Materials: Supplementary materials can be found at http:/ /www.mdpi.com/1422-0067/20/2/ $264 /$ s1.

Author Contributions: M.P.P., J.M. and A.L. were responsible for the study concept and design. S.G.-M. and C.S.-B. synthetized and analyzed quercetin sulfates. I.E. and A.M.-S. performed the cell experiments and acquired the data. I.E. performed the gene expression and bioanalytical analysis. M.P.P., A.L. and J.M. interpreted data and drafted the manuscript. All authors read and approved the final manuscript.

Funding: This research has been supported by Instituto de Salud Carlos III (CIBERobn), Basque Government (IT-572-13) and MINECO (AGL2015-64522-C2-2-R). Itziar Eseberri is a recipient of a doctoral fellowship from the University of the Basque Country. Andrea Mosqueda-Solís is a recipient of a doctoral fellowship from the CONACYT (Mexico).

Conflicts of Interest: The authors declare no conflict of interest.

$\begin{array}{ll}\text { Abbreviations } \\ \text { 3G } & \text { quercetin-3-O-glucuronide } \\ 3 S & \text { quercetin-3-O-sulfate } \\ 4 S & \text { quercetin-4-O-sulfate } \\ \text { atgl } & \text { adipose triglyceride lipase } \\ \text { bcl2 } & \text { B cell leukemia/lymphoma 2 } \\ \text { cas3 } & \text { caspase 3 } \\ \text { cebp } \alpha & \text { CCAAT-enhancer-binding protein } \alpha \\ \text { cebp } \beta & \text { CCAAT-enhancer-binding protein } \beta \\ \text { dgat1 } & \text { diacylglycerol O-acyltransferase 1 } \\ \text { dgat2 } & \text { diacylglycerol O-acyltransferase 2 } \\ \text { DMEM } & \text { Dulbecco's modified Eagle's medium } \\ \text { fasn } & \text { fatty acid synthase } \\ \text { glut4 } & \text { facilitated glucose transporter member } 4 \\ \text { FCS } & \text { fetal calf serum } \\ \text { FFA } & \text { free fatty acid } \\ \text { hsl } & \text { hormone sensitive lipase } \\ \text { ISO } & \text { isorhamnetin } \\ \text { lpl } & \text { lipoprotein lipase } \\ \text { ppar } \gamma & \text { peroxisome proliferator-activated receptor } \gamma\end{array}$




$\begin{array}{ll}\text { Q } & \text { quercetin } \\ \text { srebf1 } & \text { sterol regulatory element-binding factor 1 } \\ \text { TAM } & \text { tamarixetin } \\ \text { TG } & \text { triacylglycerol } \\ \text { trp53 } & \text { transformation related protein } 53\end{array}$

\section{References}

1. Hollman, P.C.; Katan, M.B. Dietary flavonoids: Intake, health effects and bioavailability. Food Chem. Toxicol. 1999, 37, 937-942. [CrossRef]

2. Neveu, V.; Perez-Jiménez, J.; Vos, F.; Crespy, V.; du Chaffaut, L.; Mennen, L.; Knox, C.; Eisner, R.; Cruz, J.; Wishart, D.; et al. Phenol-Explorer: An online comprehensive database on polyphenol contents in foods. Database (Oxford) 2010. [CrossRef] [PubMed]

3. Hertog, M.G.; Kromhout, D.; Aravanis, C.; Blackburn, H.; Buzina, R.; Fidanza, F.; Giampaoli, S.; Jansen, A.; Menotti, A.; Nedeljkovic, S. Flavonoid intake and long-term risk of coronary heart disease and cancer in the seven countries study. Arch. Intern. Med. 1995, 155, 381-386. [CrossRef] [PubMed]

4. Harwood, M.; Danielewska-Nikiel, B.; Borzelleca, J.F.; Flamm, G.W.; Williams, G.M.; Lines, T.C. A critical review of the data related to the safety of quercetin and lack of evidence of in vivo toxicity, including lack of genotoxic/carcinogenic properties. Food Chem. Toxicol. 2007, 45, 2179-2205. [CrossRef]

5. Zhu, J.G.; Xia, L.; Ji, C.B.; Zhang, C.M.; Zhu, G.Z.; Shi, C.M.; Chen, L.; Qin, D.N.; Guo, X.R. Differential DNA methylation status between human preadipocytes and mature adipocytes. Cell Biochem. Biophys. 2012, 63, 1-15. [CrossRef] [PubMed]

6. Siersbæk, R.; Nielsen, R.; Mandrup, S. Transcriptional networks and chromatin remodeling controlling adipogenesis. Trends Endocrinol. Metab. 2012, 23, 56-64. [CrossRef]

7. Spalding, K.L.; Arner, E.; Westermark, P.O.; Bernard, S.; Buchholz, B.A.; Bergmann, O.; Blomqvist, L.; Hoffstedt, J.; Näslund, E.; Britton, T.; et al. Dynamics of fat cell turnover in humans. Nature 2008, 453, 783-787. [CrossRef]

8. Kuppusamy, U.R.; Das, N.P. Effects of flavonoids on cyclic AMP phosphodiesterase and lipid mobilization in rat adipocytes. Biochem. Pharmacol. 1992, 44, 1307-1315. [CrossRef]

9. Hsu, C.L.; Yen, G.C. Induction of cell apoptosis in 3T3-L1 pre-adipocytes by flavonoids is associated with their antioxidant activity. Mol. Nutr. Food Res. 2006, 50, 1072-1079. [CrossRef] [PubMed]

10. Ahn, J.; Lee, H.; Kim, S.; Park, J.; Ha, T. The anti-obesity effect of quercetin is mediated by the AMPK and MAPK signaling pathways. Biochem. Biophys. Res. Commun. 2008, 373, 545-549. [CrossRef]

11. Yang, J.Y.; Della-Fera, M.A.; Rayalam, S.; Ambati, S.; Hartzell, D.L.; Park, H.J.; Baile, C.A. Enhanced inhibition of adipogenesis and induction of apoptosis in 3T3-L1 adipocytes with combinations of resveratrol and quercetin. Life Sci. 2008, 82, 1032-1039. [CrossRef] [PubMed]

12. Eseberri, I.; Miranda, J.; Lasa, A.; Churruca, I.; Portillo, M.P. Doses of Quercetin in the Range of Serum Concentrations Exert Delipidating Effects in 3T3-L1 Preadipocytes by Acting on Different Stages of Adipogenesis, but Not in Mature Adipocytes. Oxid. Med. Cell. Longev. 2015, 2015, 480943. [CrossRef] [PubMed]

13. Wood Dos Santos, T.; Cristina Pereira, Q.; Teixeira, L.; Gambero, A.; A Villena, J.; Lima Ribeiro, M. Effects of Polyphenols on Thermogenesis and Mitochondrial Biogenesis. Int. J. Mol. Sci. 2018, 19, 2757. [CrossRef] [PubMed]

14. Snyder, S.M.; Zhao, B.; Luo, T.; Kaiser, C.; Cavender, G.; Hamilton-Reeves, J.; Sullivan, D.K.; Shay, N.F. Consumption of Quercetin and Quercetin-Containing Apple and Cherry Extracts Affects Blood Glucose Concentration, Hepatic Metabolism, and Gene Expression Patterns in Obese C57BL/6J High Fat-Fed Mice. J. Nutr. 2016, 146, 1001-1007. [CrossRef] [PubMed]

15. Leiherer, A.; Stoemmer, K.; Muendlein, A.; Saely, C.H.; Kinz, E.; Brandtner, E.M.; Fraunberger, P.; Drexel, H. Quercetin Impacts Expression of Metabolism- and Obesity-Associated Genes in SGBS Adipocytes. Nutrients 2016, 8, 282. [CrossRef] [PubMed]

16. Lee, S.G.; Parks, J.S.; Kang, H.W. Quercetin, a functional compound of onion peel, remodels white adipocytes to brown-like adipocytes. J. Nutr. Biochem. 2017, 42, 62-71. [CrossRef] [PubMed] 
17. Moon, J.; Do, H.J.; Kim, O.Y.; Shin, M.J. Antiobesity effects of quercetin-rich onion peel extract on the differentiation of 3T3-L1 preadipocytes and the adipogenesis in high fat-fed rats. Food Chem. Toxicol. 2013, 58, 347-354. [CrossRef]

18. Rivera, L.; Morón, R.; Sánchez, M.; Zarzuelo, A.; Galisteo, M. Quercetin ameliorates metabolic syndrome and improves the inflammatory status in obese Zucker rats. Obesity (Silver Spring) 2008, 16, 2081-2087. [CrossRef]

19. Lee, J.S.; Cha, Y.J.; Lee, K.H.; Yim, J.E. Onion peel extract reduces the percentage of body fat in overweight and obese subjects: A 12-week, randomized, double-blind, placebo-controlled study. Nutr. Res. Pract. 2016, 10, 175-181. [CrossRef]

20. Kobori, M.; Masumoto, S.; Akimoto, Y.; Oike, H. Chronic dietary intake of quercetin alleviates hepatic fat accumulation associated with consumption of a Western-style diet in C57/BL6J mice. Mol. Nutr. Food Res. 2011, 55, 530-540. [CrossRef]

21. Panchal, S.K.; Poudyal, H.; Brown, L. Quercetin ameliorates cardiovascular, hepatic, and metabolic changes in diet-induced metabolic syndrome in rats. J. Nutr. 2012, 142, 1026-1032. [CrossRef] [PubMed]

22. Jung, C.H.; Cho, I.; Ahn, J.; Jeon, T.I.; Ha, T.Y. Quercetin reduces high-fat diet-induced fat accumulation in the liver by regulating lipid metabolism genes. Phytother. Res. 2013, 27, 139-143. [CrossRef]

23. Pfeuffer, M.; Auinger, A.; Bley, U.; Kraus-Stojanowic, I.; Laue, C.; Winkler, P.; Rüfer, C.E.; Frank, J.; Bösch-Saadatmandi, C.; Rimbach, G.; et al. Effect of quercetin on traits of the metabolic syndrome, endothelial function and inflammation in men with different APOE isoforms. Nutr. Metab. Cardiovasc. Dis. 2013, 23, 403-409. [CrossRef]

24. Yang, Y.K.; Kim, S.P. The effect of onion extract intake for 12 weeks on blood lipid and obesity index in obese university women. Korean J. Sports Sci. 2013, 22, 955-962.

25. Lee, K.H.; Lee, H.J.; Park, E.J.; Jeon, K.I. Effect of onion extracts on serum lipid and antioxidant status in healthy university female. Korean J. Community Nutr. 2008, 2, 373-379.

26. Chen, S.; Jiang, H.; Wu, X.; Fang, J. Therapeutic Effects of Quercetin on Inflammation, Obesity, and Type 2 Diabetes. Mediat. Inflamm. 2016, 2016, 9340637. [CrossRef] [PubMed]

27. Van der Woude, H.; Boersma, M.G.; Vervoort, J.; Rietjens, I.M. Identification of 14 quercetin phase II mono- and mixed conjugates and their formation by rat and human phase II in vitro model systems. Chem. Res. Toxicol. 2004, 17, 1520-1530. [CrossRef]

28. D'Andrea, G. Quercetin: A flavonol with multifaceted therapeutic applications? Fitoterapia 2015, 106, $256-271$. [CrossRef]

29. Cao, J.; Zhang, Y.; Chen, W.; Zhao, X. The relationship between fasting plasma concentrations of selected flavonoids and their ordinary dietary intake. Br. J. Nutr. 2010, 103, 249-255. [CrossRef]

30. Murota, K.; Terao, J. Antioxidative flavonoid quercetin: Implication of its intestinal absorption and metabolism. Arch. Biochem. Biophys. 2003, 417, 12-17. [CrossRef]

31. Guo, Y.; Mah, E.; Bruno, R.S. Quercetin bioavailability is associated with inadequate plasma vitamin C status and greater plasma endotoxin in adults. Nutrition 2014, 30, 1279-1286. [CrossRef] [PubMed]

32. Manach, C.; Morand, C.; Crespy, V.; Demigné, C.; Texier, O.; Régérat, F.; Rémésy, C. Quercetin is recovered in human plasma as conjugated derivatives which retain antioxidant properties. FEBS Lett. 1998, 426, 331-336. [CrossRef]

33. Day, A.J.; Mellon, F.; Barron, D.; Sarrazin, G.; Morgan, M.R.; Williamson, G. Human metabolism of dietary flavonoids: Identification of plasma metabolites of quercetin. Free Radic. Res. 2001, 35, 941-952. [CrossRef] [PubMed]

34. Justino, G.C.; Santos, M.R.; Canário, S.; Borges, C.; Florêncio, M.H.; Mira, L. Plasma quercetin metabolites: Structure-antioxidant activity relationships. Arch. Biochem. Biophys. 2004, 432, 109-121. [CrossRef] [PubMed]

35. Lee, J.; Jung, E.; Kim, S.; Huh, S.; Kim, Y.; Byun, S.Y.; Kim, Y.S.; Park, D. Isorhamnetin represses adipogenesis in 3T3-L1 cells. Obesity (Silver Spring) 2009, 17, 226-232. [CrossRef] [PubMed]

36. Herranz-López, M.; Borrás-Linares, I.; Olivares-Vicente, M.; Gálvez, J.; Segura-Carretero, A.; Micol, V. Correlation between the cellular metabolism of quercetin and its glucuronide metabolite and oxidative stress in hypertrophied 3T3-L1 adipocytes. Phytomedicine 2017, 25, 25-28. [CrossRef]

37. Zhang, Y.; Gu, M.; Cai, W.; Yu, L.; Feng, L.; Zhang, L.; Zang, Q.; Wang, Y.; Wang, D.; Chen, H.; et al. Dietary component isorhamnetin is a PPAR $\gamma$ antagonist and ameliorates metabolic disorders induced by diet or leptin deficiency. Sci. Rep. 2016, 6, 19288. [CrossRef] 
38. Chuang, C.H.; Yeh, C.L.; Yeh, S.L.; Lin, E.S.; Wang, L.Y.; Wang, Y.H. Quercetin metabolites inhibit MMP-2 expression in A549 lung cancer cells by PPAR- $\gamma$ associated mechanisms. J. Nutr. Biochem. 2016, 33, 45-53. [CrossRef]

39. Maeda, H.; Hosokawa, M.; Sashima, T.; Takahashi, N.; Kawada, T.; Miyashita, K. Fucoxanthin and its metabolite, fucoxanthinol, suppress adipocyte differentiation in 3T3-L1 cells. Int. J. Mol. Med. 2006, 18, 147-152. [CrossRef]

40. Maeda, H.; Saito, S.; Nakamura, N.; Maoka, T. Paprika Pigments Attenuate Obesity-Induced Inflammation in 3T3-L1 Adipocytes. ISRN Inflamm. 2013, 2013, 763758. [CrossRef]

41. Eseberri, I.; Lasa, A.; Churruca, I.; Portillo, M.P. Resveratrol metabolites modify adipokine expression and secretion in 3T3-L1 pre-adipocytes and mature adipocytes. PLoS ONE 2013, 8, e63918. [CrossRef] [PubMed]

42. Takahashi, K.; Uchida, N.; Kitanaka, C.; Sagara, C.; Imai, M.; Takahashi, N. Inhibition of ASCT2 is essential in all-trans retinoic acid-induced reduction of adipogenesis in 3T3-L1 cells. FEBS Open Bio 2015, 5, 571-578. [CrossRef]

43. Boesch-Saadatmandi, C.; Loboda, A.; Wagner, A.E.; Stachurska, A.; Jozkowicz, A.; Dulak, J.; Döring, F.; Wolffram, S.; Rimbach, G. Effect of quercetin and its metabolites isorhamnetin and quercetin-3-glucuronide on inflammatory gene expression: Role of miR-155. J. Nutr. Biochem. 2011, 22, 293-299. [CrossRef] [PubMed]

44. Russo, M.; Spagnuolo, C.; Tedesco, I.; Bilotto, S.; Russo, G.L. The flavonoid quercetin in disease prevention and therapy: Facts and fancies. Biochem. Pharmacol. 2012, 83, 6-15. [CrossRef]

45. Aguirre, L.; Arias, N.; Macarulla, M.T.; Gracia, A.; Portillo, M.P. Beneficial Effects of Quercetin on Obesity and Diabetes. Open Nutraceuticals J. 2011, 4, 189-198.

46. Gonzales, A.M.; Orlando, R.A. Role of adipocyte-derived lipoprotein lipase in adipocyte hypertrophy. Nutr. Metab. (Lond.) 2007, 4, 22. [CrossRef]

47. Tinahones, F.J.; Coín Aragüez, L.; Murri, M.; Oliva Olivera, W.; Mayas Torres, M.D.; Barbarroja, N.; Gomez Huelgas, R.; Malagón, M.M.; El Bekay, R. Caspase induction and BCL2 inhibition in human adipose tissue: A potential relationship with insulin signaling alteration. Diabetes Care 2013, 36, 513-521. [CrossRef]

48. Molchadsky, A.; Rivlin, N.; Brosh, R.; Rotter, V.; Sarig, R. p53 is balancing development, differentiation and de-differentiation to assure cancer prevention. Carcinogenesis 2010, 31, 1501-1508. [CrossRef]

49. Lee, J.; Jung, E.; Hwang, W.; Kim, Y.S.; Park, D. Isorhamnetin-induced anti-adipogenesis is mediated by stabilization of beta-catenin protein. Life Sci. 2010, 86, 416-423. [CrossRef]

50. Dueñas, M.; González-Manzano, S.; Surco-Laos, F.; González-Paramas, A.; Santos-Buelga, C. Characterization of sulfated quercetin and epicatechin metabolites. J. Agric. Food Chem. 2012, 60, 3592-3598. [CrossRef]

51. Livak, K.J.; Schmittgen, T.D. Analysis of relative gene expression data using real-time quantitative PCR and the 2(-Delta Delta C(T)) Method. Methods 2001, 25, 402-408. [CrossRef] [PubMed] 